\title{
Los verbos zoomórficos de habla como representación léxica de la fuerza ilocutiva en checo
}

\author{
José Alejandro CALERo DíAZ \\ Universidad de Granada \\ jacalero@ugr.es
}

Recibido: Mayo de 2012

Aceptado: Enero de 2013

\section{Resumen}

El presente artículo trata de demostrar que la metáfora zoomórfica en los verbos de habla en checo tiene la capacidad de describir la fuerza ilocutiva desde dos dimensiones o niveles lingüísticos diferentes. Por un lado, las características que le son atribuidas a los animales y que se extienden metafóricamente al dominio del hombre y, por otro lado, la representación léxica que cada hablante checo tiene sobre la entonación que se le atribuye a cada verbo o manera de hablar y de la cual, también, se puede descodificar la fuerza ilocutiva.

Palabras clave: zoomórfico, verbos de habla, ilocutivo, entonación

Zoomorphic Speech Verbs and the Lexical Representation of the Illocutionary Force in Czech Language

\begin{abstract}
The intention of this paper is to defend that the zoomorphic metaphors in speech verbs of czech language represent the illocutionary force through two different linguistic dimmentions. First, they extend -metaphorically- the animal characteristics to the human lexical domain, and second, these verbs represent lexically different manners of speaking, therefore their lexical meanings reflect the illocutionary force or speech intentions.
\end{abstract}

Key words: zoomorphic, speech verbs, illocutionary, intonation

La metáfora zoomórfica es, tal vez, una de las más productivas en el dominio léxico MLUVIT, es decir, dentro de la familia léxica de los verbos de habla checos. Este tipo de metaforización la podemos simplificar parafraseándola mediante la sentencia "las personas son animales" que según ECHEVARRÍA (2003: 5) representa una metáfora de mayor rango o metáfora conceptual siguiendo la tradición abierta por LAKOFF (1980a, 1980b). 
Esta corriente lingüística conocida como Lingüística Cognitiva afirma que los distintos fenómenos de figuratividad le sirven al hablante, sobre todo, para designar y comprender "una cosa en términos de otra" y no sólo como elemento estético o literario (CHAMIZO 1998: 9-10; ECHEVARRIA 2003: 3).

La génesis de este tipo de metaforizaciones está imbricada en la visión antropocentrista y antropomórfica del hombre hacia la realidad que le rodea por defecto. Esta circunstancia es, en gran medida, responsable del carácter no sólo descriptivo sino también valorativo del lenguaje, que nos conduce a describir y valorar la realidad positivamente cuando se cumplen los condicionamientos físicos y biológicos propios del hombre y, negativamente, cuando dichos condicionamientos no se cumplen.

Krzeszowski propone una escala basada en el factor humano (1990: 157), que se corresponde de forma analógica con los diferentes grados de metaforización y valoración. En los niveles más bajos se encontrarían los objetos inanimados, y de éstos se pasaría a los animales hasta terminar en los seres humanos.

Además, propone una metodología que resolvería en parte alguno de los problemas inherentes al parámetro axiológico-valorativo, que se basa en la noción de Modelos Cognoscitivos Idealizados de LAKOFF (1982) y en la noción de metáfora, tal y como la concibieron LAKOFF (1980a; 1980b).

Para Lakoff y Johnson las metáforas se pueden organizar sistemáticamente a base de lo que denominan orientational metaphors, es decir, a partir de la orientación en el espacio: up-down, in-out, from-back, on-off, deep-shallow, central-peripherical, donde los primeros valores son los positivos. ${ }^{1}$ A través de las orientational metaphors los autores mencionados consiguen ubicar determinadas expresiones metafóricas dentro de una sola totalidad comparable: UP-DOWN como experiential basis (LAKOFF, 1980a: 20):

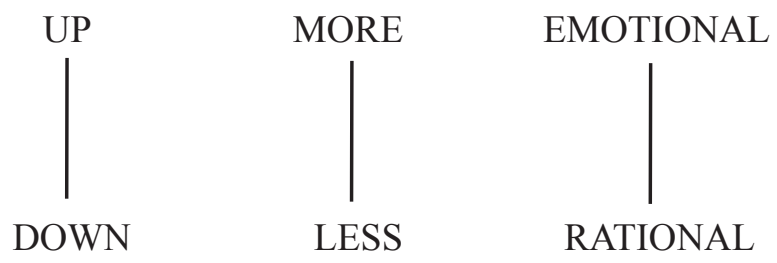

Una de las mayores dificultades que afrontamos al describir los verbos zoomórficos de habla en checo estriba en el doble carácter que poseen, por un lado, el carácter descriptivo de la manera de hablar y que afecta, sobre todo, a la capacidad descriptiva del sonido y, por otro lado, al carácter figurativo que permite que determinadas características que se le atribuyen a animales se extiendan al hombre. Tomemos como ejemplo las acepciones que los diccionarios checos Slovník spisovné češtiny y Slovník jazyka českého (respectivamente y en adelante, SSČ y SJČ) muestran sobre el lexema zoomórfico bručet, la traducción de dichas acepciones es nuestra:

\footnotetext{
${ }^{1}$ Lakoff y Johnson estudian una serie de expresiones metafóricas a través de la orientación espacial: "HAPPY IS UP - SAD US DOWN"; "CONSCIUS IS UP - UNCONSCIUS IS DOWN"; "GOOD IS UP - BAD IS DOWN"; "RATIONAL IS UP - IRRATIONAL IS DOWN” (LAKOFF 1980: 15).
} 
[SSČ]: vydávat temný a nejasný zvuk (medvěd, basa) = emitir sonidos oscuros y opacos (por ejemplo: un oso, un bajo). 2. nejasně rríkat, zpívat, broukat (písničku) = decir, cantar, canturrear (una canción) de manera poco clara. 3. expr. hubovat, reptat, brblat = regañar, rezongar, refunfuñar

[SJČ]: vydávat hluboké zvuky = emitir sonidos profundos; mumlat $=$ mascullar; reptat $=$ regañar; hubovat $=$ refunfuñar

De esta manera, el verbo bručet es un verbo onomatopéyico de habla que describe la calidad del sonido y este significado es expresado mediante una única entrada en el diccionario [SJČ] vydávat hlub oké zvuky, así como por el significado de la primera entrada temný a nejasný zvuk del diccionario [SSČ] y por el modificador adverbial de la segunda entrada nejasně del mismo diccionario [SSČ]. Aparte de estas acepciones que implican un significado meramente descriptivo, el significado de la primera acepción (emitir sonidos un oso) corrobora que los significados que refieren SONIDO HUMANO se ubican en dicho subdominio como extensiones metafóricas del primer significado, perteneciente al subdominio de SONIDO ANIMAL.

En este sentido, es importante recordar que tanto las connotaciones metafóricas como la capacidad descriptiva del sonido, reflejada por gran parte de los verbos zoomórficos de habla, tienen un marcado carácter indicial con respecto a la fuerza ilocutiva codificada por el verbo. El carácter indicial del acto ilocutivo resulta difícil de analizar, debido precisamente a la doble naturaleza descriptiva-figurativa de gran parte de estos verbos, que provoca a su vez que se puedan considerar como verbos onomatopéyicos y como metafóricos.

\section{La fuerza ilocutiva inadecuada y/o socialmente reprochable}

La concepción tradicional tanto de fuerza ilocutiva como de acto ilocutivo parte de la perspectiva de la $1^{\mathrm{a}}$ persona y describe toda una serie de condiciones y premisas necesarias para el éxito de la misma (la fuerza ilocutiva) que dependen, sobre todo, de las intenciones de dicha persona, la $1^{\text {a }}{ }^{2}$ Sin embargo, vamos a centrar nuestra atención a aquellas teorías pragmático-funcionalistas, que dejan expedito el camino a un estudio de la fuerza ilocutiva dependiente, además, de ciertas condiciones contextuales o ambientales. Por lo tanto, nuestro estudio partirá desde otra perspectica, aquella que se centra también en las intenciones ilocutivas atribuidas a terceras personas (BLANCO 2008; CALERO DÍAZ 2010; CALERO DÍAZ 2012: 113).

Desde el Funcionalismo y la Pragmática, HIRSCHOVÁ (1988: 16-25), recurriendo a las teorías desarrolladas por DANEŠ (1973: 120-121), se planteó cómo deben analizarse las intenciones del hablante frente al oyente y frente a la información proferida. Ambos autores, aunque sobre todo Hirschová, a la vez que describían el mapa intencional de los actos de habla, sentaron las bases para un estudio de los verba dicendi checos (aplicable a otras lenguas) desde un punto de vista conversacional.

\footnotetext{
${ }^{2}$ Esto se debe a que la base sobre la que se fundamentan los verbos ilocutivos se encuentra en el uso performativo o realizativo de sus predicados. Es decir, que si con la $1^{\text {a }}$ persona del singular del presente de indicativo en voz activa realizamos explicitamente el "acto" que estamos diciendo, entonces nos encontramos ante un verbo y un acto ilocutivo según (AUSTIN 1962:69): Por ejemplo: I shall be there - hereby - I promise that I shall be there.
} 
En primera instancia, Hirschová describió el mapa jerárquico de las relaciones hablante-oyente mediante el cual se rigen los verbos que expresan actos de habla en checo:

1. El hablante es superior al destinatario.

2. El destinatario es superior al hablante.

3. Hablante y destinatario son participantes equivalentes.

4. La relación hablante y destinatario no está especificada.

Así, por ejemplo, cuando el hablante es superior al destinatario emplea actos ilocutivos del tipo: ordenar, prohibir, etc. (rozkázat, zakázat) mientras que en la relación contraria emplea actos ilocutivos del tipo: rogar, suplicar, etc. (prosit, žádat).

El segundo parámetro propuesto por Hirschová está relacionado con el contenido de la información y la relación que se genera entre información y hablante-destinatario:

1. contenido de la información;

2. a)-relación mental del hablante hacia la información;

b)-relación ventajosa (interesada) del hablante hacia la información;

3. a)-relación mental del destinatario hacia la información;

b)-relación ventajosa (interesada) del destinatario hacia la información.

\section{Comparación entre dominios léxicos}

Entendemos que en el análisis de los procesos metafóricos es conveniente contrastar los dos dominios léxicos que entran en juego, es decir, el dominio de origen y el dominio hacia el que se extiende la metáfora, ya que las propiedades del agente del primer dominio (dominio de origen) se asocian a las propiedades del segundo dominio, que en el caso de las metáforas zoomórficas consistirá en propiedades animales extendidas al hombre.

\begin{tabular}{|l|l|}
\hline $\begin{array}{l}\text { DOMINIO SONIDO (agente } \\
\text { mamifero doméstico: perro, gato) }\end{array}$ & DOMINIO MLUVIT \\
\hline bafat: ladrar & $\begin{array}{l}\text { bafat: decir con fuerza, violentamente, en tono } \\
\text { amenazante }\end{array}$ \\
\hline štěkat: ladrar & $\begin{array}{l}\text { štěkat: decir con fuerza, violentamente, con vehe- } \\
\text { mencia, en tono amenazante }\end{array}$ \\
\hline vrčet: gruñir & vrčet: gruñir \\
\hline $\begin{array}{l}\text { kňourat/kníčet,kňučet: maullar, } \\
\text { mayar }\end{array}$ & $\begin{array}{l}\text { ǩnourat/knícet,kňučet,mňoukat: rogar, pedir, } \\
\text { suplicar insistentemente, encarecidamente y llori- } \\
\text { queando }\end{array}$ \\
\hline broukat: gimotear & $\begin{array}{l}\text { broukat: berrear, cantar desentonadamente, pro- } \\
\text { testar quejosamente }\end{array}$ \\
\hline mňoukat: maullar & mňoukat: pedir lloriqueando \\
\hline
\end{tabular}


Hemos podido observar que los lexemas del dominio léxico MLUVIT expresan diferentes tipos de fuerza ilocutiva: las formas kn̆ourat-pedir, rogar, suplicar de manera llorosa, etc., y la forma broukat que designa protestar, también, de manera quejosa (como lo haría un perro), aunque ambas formas pueden coincidir en su contenido semántico-pragmático, es decir, pueden designar tanto protesta como petición 3 . De la presente información semántico-pragmática se deduce implícitamente la fuerza ilocutiva codificada en las curvas melódicas que reflejan tales verbos. Éste es, también, el caso de los lexemas bafat, štěkat que expresan la fuerza ilocutiva amenazar.

\begin{tabular}{|l|l|}
\hline $\begin{array}{l}\text { DOMINIO SONIDO (agente mamifero } \\
\text { grande y agresivo: oso, león) }\end{array}$ & DOMINIO MLUVIT \\
\hline bručet: gruñir & bručet: refunfuñar \\
\hline rvát: rugir & řvát: gritar \\
\hline
\end{tabular}

Observamos que la fuerza ilocutiva en bručet-refunfuñar y broukat-protestar quejándose es la misma. Su diferencia estriba en la posición que ocupan los hablantes frente al destinatario: bručet - hablante superior/igual a oyente vs. broukat hablante inferior a oyente. Estas observaciones tienen su correlato en las diferentes asociaciones derivadas de los agentes de la acción verbal en los dominios de origen, mientras que los osos, leones, etc. se presentan como animales poderosos, los cachorros, gatitos, etc. se presentan como animales desamparados.

\begin{tabular}{|l|l|}
\hline $\begin{array}{l}\text { DOMINIO SONIDO (agente insecto } \\
\text { volador: mosca, avispa, etc.) }\end{array}$ & DOMINIO MLUVIT \\
\hline bzučet/bzikat: zumbar (un insecto) & $\begin{array}{l}\text { bzučet/bzikat: zumbar, canturrear, hablar } \\
\text { produciendo sonidos silbantes (desagrada- } \\
\text { bles para el oyente). }\end{array}$ \\
\hline
\end{tabular}

\begin{tabular}{|l|l|}
\hline DOMINIO SONIDO (agente gallinácea) & DOMINIO MLUVIT \\
\hline $\begin{array}{l}\text { hudrovat: emitir los sonidos característi- } \\
\text { cos del pavo = gluglutear }\end{array}$ & $\begin{array}{l}\text { hudrovat: refunfuñar, regañar, mostrar } \\
\text { descontento. }\end{array}$ \\
\hline kdákat: emitir el sonido kdák = cloquear & $\begin{array}{l}\text { kdákat: charlar, charlotear, chacharear, } \\
\text { hablar mucho, hablar sin sentido. }\end{array}$ \\
\hline $\begin{array}{l}\text { tokat: emitir el sonido característico del } \\
\text { urogallo ( por un urogallo ) = zurear, } \\
\text { arrullar. } \\
\text { vrkat: } \text { arrullar }\end{array}$ & $\begin{array}{l}\text { tokat: galantear (un hombre a una mujer). } \\
\text { vrkat: hablar amorosamente. }\end{array}$ \\
\hline
\end{tabular}

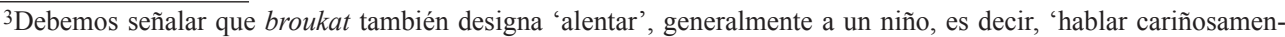
te/en tono alentador'.
} 
Los lexemas vrkat y tokat implican otro acto perlocutivo de diferente carácter: galantear, flirtear (con sentido valorativo negativo), hablar demasiado amorosamente, hablar de manera insistente, intentar seducir, etc. Ambos lexemas llevan implícito asociaciones relacionadas con el celo animal, si bien, el lexema vrkat es más neutro que el segundo, ya que podríamos decir que designa a ambos sexos, en cuanto que tokat, por el contrario, designa siempre al macho (el urogallo) y a su consecuente actividad insistente y solitaria de la seducción a la hembra.

\begin{tabular}{|l|l|}
\hline $\begin{array}{l}\text { DOMINIO SONIDO } \\
\text { (agente córvido })\end{array}$ & DOMINIO MLUVIT \\
\hline $\begin{array}{l}\text { krákat, krákorat, etc., emitir el } \\
\text { sonido krá(k) = graznar, grajear }\end{array}$ & krákat: hablar mucho, sin sentido. \\
\hline
\end{tabular}

Los sonidos emitidos por córvidos y aves de corral se extienden metafóricamente hacia el dominio MLUVIT cuando el agente es representado, por lo general, por una mujer (mayor). Las consiguientes repercusiones de este hecho nos conducen, en un análisis de la valoración en el léxico, a incidir en que el carácter ontológico de la metáfora zoomórfica conlleva, en muchos casos, la superioridad (a través de la metáfora orientacional; ARRIBA-ABAJO, BUENO-MALO) del género masculino sobre el femenino. Parece que la asociación gallina/cuervo-mujer mayor es universal, al menos, en muchas lenguas europeas y que, en el caso de los verbos onomatopéyicos de habla, no ocurre sólo en virtud de las propiedades sonoras reflejadas por ellos sino, también, a través de las características negativas que se les asignan a ambos referentes: desagradable, ruidoso, afinidad con otros de su especie, descortesía, cobardía, etc.

\begin{tabular}{|l|l|}
\hline $\begin{array}{l}\text { DOMINIO SONIDO } \\
\text { (agente ranas) }\end{array}$ & DOMINIO MLUVIT \\
\hline $\begin{array}{l}\text { kuňkat: emitir el sonido kuň }(k)= \\
\text { croar, groar, charlear. } \\
k v a ́ k a t: \text { emitir el sonido kvá(k)= } \\
\text { croar, groar, charlear }\end{array}$ & $\begin{array}{l}\text { kuňkat: berrear, cantar desafinando. } \\
\text { kvákat: hablar mucho, sin sentido. }\end{array}$ \\
\hline $\begin{array}{l}\text { DOMINIO SONIDO (agente } \\
\text { burro, córvido) }\end{array}$ & DOMINIO MLUVIT \\
\hline $\begin{array}{l}\text { hejkat/hýkat: emitir un sonido } \\
\text { prolongado parecido a hý }= \\
\text { rebuznar (el burro); graznar (un } \\
\text { córvido). }\end{array}$ & $\begin{array}{l}\text { hejkat/hýkat: gritar, hablar, decir en voz alta } \\
\text { algo inportancia. }\end{array}$ \\
\hline
\end{tabular}


En este cuadro, el dominio léxico MLUVIT incluye una crítica al nivel intelectual del hablante: hablar como un burro. Lo mismo ocurre en el cuadro posterior.

\begin{tabular}{|l|l|}
\hline $\begin{array}{l}\text { DOMINIO SONIDO } \\
\text { (agente bovino) }\end{array}$ & DOMINIO MLUVIT \\
\hline $\begin{array}{l}\text { bučet: emitir el sonido bú, equi- } \\
\text { valente al español "mú" = mugir, } \\
\text { bramar. }\end{array}$ & bučet: gritar (como forma de protesta), protestar. \\
\hline
\end{tabular}

Este lexema, al igual que el anterior, califica negativamente el nivel intelectual del hablante. Además, cabe señalar que este lexema suele denotar a un agente colectivo, es decir, los agentes que desarrollan la acción, son hablantes cuyo comportamiento se asocia metafóricamente al del ganado.

\section{Verbos zoomórficos de habla como representación léxica de la entonación}

En este apartado pretendemos defender que los verbos zoomórficos son entendidos por la comunidad lingüística checa, junto con otros verbos onomatopéyicos de habla, como representaciones léxicas de la entonación y que la entonación, a su vez, simboliza o indica el tipo de acto ilocutivo que se está realizando (CALERO DÍAZ 2010: 209-77).

La entonación, según BOLINGER (1983) y DANEŠ (1985), es percibida por las comunidades lingüísticas de manera parecida a los gestos, por ejemplo: cuando hablamos de manera tosca, irónica, enojada o cariñosamente. En virtud de este nivel de interpretación cuasi paralingüístico la entonación ha sido entendida como un fenómeno de "iconicidad primitiva".

Se trata también, en realidad, de un fenómeno de sinestesia, ya que el hablante es capaz de experimentar gestos que no realiza. Según Daneš el oyente puede reconocer, gracias a la forma acústica de la elocución, si el hablante le está pidiendo u ordenando algo, si es reservado o si se compadece, etc., es decir, puede reconocer determinados tipos de actos ilocutivos entre otros eventos. Según esta afirmación, la relación entre fuerza ilocutiva y entonación puede ser estudiada a través del análisis de sus características indiciales o icónicas.

Daneš le da una explicación neuropsicológica al carácter icónico de la entonación, que nace del comportamiento híbrido del cerebro, es decir, el hemisferio derecho tiene un comportamiento analógico y el hemisferio izquierdo digital que se corresponde con el principio binario sí/no. Gracias al principio analógico del cerebro se explica con claridad que el funcionamiento de la entonación pueda ser caracterizado como gradual (más-menos), como ocurre con el descenso entonativo, puede ser más o menos conclusivo según el caso. Incluso los grados de intensidad emocional pueden encontrar su correlato por medio de la gradación de los diferentes seg- 
mentos de la curva melódica. Es por ello que Daneš insta a un estudio alejado de los parámetros de la gramática o al menos no basado únicamente en éstos: "partiendo de una base psicofisiológica de la entonación se desprende su uso extendido en el nivel emocional" (DANEŠ 1985: 86).

Mediante el principio analógico de carácter gradual operan, a su vez, los mecanismos de mitigation/reforcement de la fuerza ilocutiva señalados por HOLMES (1984). Por otro lado, el carácter gradual del comportamiento entonativo tiene una de sus manifestaciones más patentes en las distancias entre tonos (pitches o acentos tonales); lo que podemos denominar (en términos musicales) como intervalos tonales (GARDINER 1980). A nivel semántico-funcional, los intervalos tonales son indicios de la pertenencia a determinados tipos de actos de habla y, entre ellos, también los actos de diálogo (CALERO DÍAZ 2010), así como la expresión de la modalidad oracional, es decir, si se trata de una oración asertiva, interrogativa, etc.

\section{Actos de diálogo}

Debemos entender el término "Acto de diálogo" como "Acto de habla dentro del diálogo". BUNT (2005) nos indican que el "Acto de diálogo" debe ser estudiado a partir de dos grandes aspectos: 1. semántico (o referencial, proposicional) y 2. su función o intención comunicativa. En la suma de ambos aspectos reconocemos la premisa comunicativa a la que podemos denominar "intercambio informativo". De esta manera, surge el concepto feedback dentro de los estudios de los "actos de diálogo" (BUNT 2005: 2), el cual se puede traducir al español bajo los equivalentes retroalimentación, reacción, eco o si se prefiere como respuesta.

Este tipo de consideración nos facilita la creación de una taxonomía de los tipos de entonación reflejada por los verbos que dependa de premisas y principios de colaboración, aunque también de las intenciones reales del hablante por colaborar, ser escuchado, atendido, etc., así como de la posición de éste ante su interlocutor.

\section{Entonación y música}

Gardiner en su trabajo sobre la semántica de la prosodia checa, observa las semejanzas existentes entre la entonación de algunas lenguas europeas y la música, de manera que los elementos constituyentes que describe son susceptibles de ser utilizados tanto en el análisis de la prosodia como en el de la música (GARDINER 1980: 3-6): cesura, acento, pitch y cadencias. Nos centraremos en la definición de pitch y cadencia, ya que a través de dichos términos hemos establecido una serie de valores semánticos (GARDINER 1980; CALERO DÍAZ 2010: 214-35).

Consideramos que el comportamiento de la entonación es igual al de la música en el sentido de que está vertebrada por dos ejes: el temporal y el de la escala tonal. Esto facilita la clasificación jerárquica del pitch, integrado en cada cadencia, y la extracción de sus valores semánticos.

PITCH: el concepto de pitch se corresponde al de acento tonal o pico. Gardiner propone cuatro pitches estructurales: tónica, tercera, quinta y octava (relativas a una escala gradual) que componen las melodías entonativas. Cada uno de los cuatro pit- 
ches tiene un significado abstracto invariable que se relaciona con diferentes tipos de significados variables contextuales dependientes de la posición estructural en la que tengan lugar (GARDINER 1980: 5).

Los conceptos de tónica, segunda, tercera, cuarta, quinta, sexta, séptima y octa$v a$ deben ser entendidos sólo desde el punto de vista melódico, puesto que el lenguaje musical también contempla la dimensión armónica. Aquí se emplearán dichos términos para explicar las diferentes distancias existentes entre acentos tonales. Por ejemplo, la tónica refleja el centro tonal (o rango tonal normal) del hablante, en una escala natural como la escala de do, la tónica estaría representada por el primer grado tonal, es decir, do, de ahí que se considere como punto de reposo, final o de descanso. La segunda está representada por re, la tercera por mi, y así sucesivamente hasta llegar a la octava que representa el octavo grado dentro de una escala. En la misma escala de do, dicha octava con respecto a su tónica sería de nuevo do, aunque siete tonos más aguda. ${ }^{4}$

Los significados o valores invariables de los pitches dependen del lugar que ocupan dentro de la escala: la tónica tiene un valor "no marcado", la quinta significa "mayor grado", la octava significa "grado extra", la tercera "menor grado".

CADENCIAS: siguiendo la terminología de la teoría musical, las cadencias son la cesura y el pitch de la sílaba que la precede, tomados como un todo. A dicho pitch se le conoce como pitch cadencial. Toda cadencia es entendida como un "grado de separación". Cualquier pitch mayor que la tónica está marcado y, por lo tanto, tendrá una conexión semántica con la frase que le sigue. La cadencia de tónica (o si se prefiere, hacia la tónica) significa "separación normal", "frases normales", "no son necesarias más frases", etc., la cadencia de quinta significa "falta de separación normal", la cadencia de octava significa "separación mayor de lo normal", y la cadencia de tercera significa "separación menor de lo normal".

La cadencia de tónica implica que no continúa el discurso, la cadencia de octava, por el contrario, expresa un mayor grado de insistencia en que la información o la frase continúen. Por lo tanto frecuentemente, aunque no siempre, la encontraremos en estructuras interrogativas conocidas como yes/no questions donde el hablante indica al receptor que complete el diálogo con una respuesta. Las cadencias de quinta y tercera indican en menor grado la insistencia del hablante en que la información deba o no ser terminada (continuada), por lo que tienen lugar en frases suspensivas en tanto en cuanto a éstas les siguen otras frases. La octava es una referencia al diálogo, ya que este hecho requiere la respuesta por parte del receptor, aunque también se usa como modo de indicar que la oración queda eventualmente suspendida:

Intonational patterns also have these hierarchical scale forms, since relatively higher pitches are used in canonical yes/no questions, only relatively low pitches conclude completed statements, only mid-pitches occur in non-final cadences, etc. (GARDINER 1980: 49).

VAN SCHOONEVELD (1961: 91) analiza las estructuras de pitch que forman los intervalos y les otorga los siguientes valores: de tercera "smaller than dialogue", es decir, menor prototipicidad de diálogo, los intervalos de quinta "smaller than sta-

\footnotetext{
${ }^{4}$ Para un conocimiento más profundo sobre los diferentes grados tonales véase la monografía Teoría musical y armonía moderna de HERRERA (1995).
} 
tement", es decir, mayor protipicidad de aseveración y, por último, los intervalos de octava son la suma de los dos, marcan estructuras "smaller than dialogue or statement $=$ yes/no question".

El carácter icónico de la octava entonativa es universal, ya que la octava tiene la capacidad de introducir predicaciones ajenas y no contemporáneas, es decir, tiene la capacidad mímica de hacer referencia al diálogo. Es fácilmente corroborable que el hablante, en muchas ocasiones, cuando refiere un enunciado ajeno y/o anterior recurre a subir su rango tonal una octava (o cerca de la octava).

Según Gardiner, en realidad, los intervalos tonales presentan los siguientes valores icónico-semánticos: la quinta denota "smaller than dialogue" (límites dentro de la locución), la tercera denota "smaller than utterance" (estructuras dentro de la frase), mientras que la octava combina ambas. El autor postula, implícitamente, una especie de principio que denominamos Principio de Iconicidad Entonativa (CALERO DÍAZ 2010: 223): "the more pitches an utterance has, the more subtle and complex are its semantics, the more finely-gradated is its affective message"

Así pues, afirmamos que existe una gradación tonal corroborada por los contenidos semánticos de los verbos que reflejan las curvas melódicas apuntadas, y que ordenamos según dicha gradación de menor a mayor:

- Verbos zoomórficos que reflejan cadencias progresivas y que expresan "mascullar una protesta, hablar entre dientes": bručet, mručet.

- Verbos onomatopéyicos (no zoomórficos) que reflejan cadencias conclusivas y que se corresponden con el subdominio léxico "aseverar, afirmar, ordenar, enunciar, pregonar, etc.": hlásit, hlásat, etc.

- Verbos zoomórficos que reflejan anticadencias y que se corresponden con el subdominio léxico "pedir, rogar, suplicar, quejarse, lloriquear, lamentarse, hablar amorosamente": knírat, kňučet, fñučet, kňourat, broukat, etc.

\section{Grados de asertividad y directividad}

Como se ha visto, Gardiner contempla, casi en exclusiva, la prototipicidad de los actos asertivos reflejados por la curva melódica dentro de la elocución. Aquí la mayor prototipicidad asertiva depende, como ha quedado patente, de la mayor distancia del intervalo hacia una tónica, que consideramos Gardiner identifica, sistemáticamente, con la tónica de la frase o elocución.

Asimismo, se ha hecho patente en nuestras investigaciones que las distancias tonales que reflejan mayor prototipicidad directiva no se comprenden únicamente como relaciones o valores tonales dentro de la elocución, sino más bien como valores tonales existentes entre la elocución y la tónica natural del hablante (CALERO DÍAZ 2010: 232), aquello a lo que comúnmente denominamos como "tonillo", dicho de otro modo, las subidas o descensos en el rango tonal (natural) del hablante.

Gardiner describía, implícitamente, que las elocuciones con mayor prototipicidad directiva son las oraciones interrogativas averiguativas (o yes/no-questions). Sin embargo, de nuevo, su análisis está enfocado hacia las diferentes modalidades oracionales y no hacia la prototipicidad ilocutiva. 
Por ello, se hace necesario señalar que la posible escala tonal que representan los diferentes grados de prototipicidad directiva no está basada en su aproximación a la tónica sino todo lo contrario, y que, además, no se contemplan como relaciones de intervalos ascendentes o descendentes, sino como la suma de éstos (en la elocución) al valor de la distancia entre la tónica o rango natural del hablante y la tónica de la frase (siempre que ésta sea superior a aquella). Es decir, aquí valoramos las diferencias entre el tono usado normalmente por el hablante (su tonalidad natural) y el tono o "tonillo" usado a la hora de proferir una frase determinada.

Por lo tanto, aquellos pitches que descansen en la tónica natural del hablante o debajo de ella mostrarán mayor prototipicidad asertiva que aquellos que, por el contrario, tengan valores tonales superiores a dicha tónica que, por el contrario, mostrarán mayor prototipicidad directiva. Esta prototipicidad directiva irá en aumento según su distancia.

A la vista de esta circunstancia, precisamos hablar de dos tipos de relaciones entonativas: 1. las intraelocutivas o relaciones entre pitches dentro de la elocución y 2. las interelocutivas o relaciones entre los pitches de la elocución con respecto al rango o tono natural del hablante.

Sobre la directividad entonativa operan, al igual que en el caso de la asertividad entonativa, escalas de fuerza ilocutiva: mitigación o atenuación frente a reforzamiento (HOLMES 1984; SBISÁ 2001), así como la posición jerárquica del hablante frente al oyente (superior/inferior) y su postura ante la información: interesada/desinteresada (HIRSCHOVÁ 1988).

De igual manera, son interesantes para el análisis que llevamos a cabo las conclusiones acerca de la directividad a las que llegan algunos estudios cognitivos, así como las escalas de directividad que se aplican en dichos estudios (RUIZ DE MENDOZA 1993, RUIZ DE MENDOZA 1994, PÉREZ FERNÁNDEZ 1996, PÉREZ FERNÁNDEZ 2000).

Los autores mencionados basan el estudio de los actos directivos en presupuestos teórico-cognitivos que ya vienen usándose en el presente trabajo (LAKOFF 1980a y 1980b) y que, para el reconocimiento de "lo elocutivo", han evolucionado en lo que se ha dado en llamar Modelo Cognitivo Idealizado (MCI) proposicional (o propositional ICM, en inglés) (LAKOFF 1987).

Asimismo, para la comprensión del comportamiento gradual de la directividad (concretamente, de las órdenes) utilizamos una serie de variables tomadas de otros estudios: coste-beneficio, opcionalidad, indirección, poder (social) (LEECH 1983):

COSTE-BENEFICIO: la valoración de un coste/beneficio que la acción A implica para el hablante/oyente.

OPCIONALIDAD: una orden prototípica no deja prácticamente ninguna libertad al oyente para decidir si desea realizar la acción que se le pide o no. Este bajo grado de opcionalidad se consigue mediante el uso de expresiones breves, directas, sin ningún tipo de mecanismo mitigador que minimice la fuerza del acto de habla (PÉREZ FERNÁNDEZ 2000: 386).

INDIRECCIÓN: las órdenes más prototípicas se efectúan de manera explícita y directa.

PODER: la valoración del grado de autoridad de un hablante sobre su oyente. 
Otra aportación recogida para el MCI es la creación de una serie de "escenarios elocutivos" para medir la escala de deseo del hablante ante la posibilidad de que una acción se acometa (THOMBURG 1997, PANTHER 1998).

\section{Simulación de la entonación representada por el léxico}

A continuación pretendemos demostrar la validez de las hipótesis expuestas con anterioridad. Dichas tesis son principalmente dos: 1. que los verbos zoomórficos, así como otros verbos onomatopéyicos checos tienen la capacidad de evocar en la comunidad lingüística checa determinadas propiedades entonativas, es decir, que existe un correlato léxico de la entonación y 2. que dichas propiedades entonativas, descritas por el léxico, son síntoma e indicio de las intenciones ilocutivas del hablante reflejadas por un verbo determinado (en nuestro caso: verbos zoomórficos de habla).

A través del ČNK (Corpus Nacional Checo) extrajimos textos contiguos a verbos que demuestran determinados comportamientos entonativos en la emisión del acto de habla. Entendemos que dichos comportamientos entonativos deben tener a priori un carácter marcado, es decir, no se trata de verbos tales como mluvit-hablar, tvrdit-afirmar, etc., que forman parte del domino léxico MLUVIT o cercanos a él. El siguiente paso ha consistido en filtrar el resultado para obtener verbos que apareciesen en tiempo pasado. A resultas de esto obtuvimos en las respuestas del ČNK la sintaxis Vpasado: "texto", lo que facilitó nuestra búsqueda, ya que pretendíamos encontrar los siguientes tipos de fragmentos:

- "Mám plán", bručel... - "Tengo un plan", refunfuñó...

- "Nojo, Gomezi” kňourala... - "Pues claro que sí, Gómez" gimoteó...

Una vez seleccionados los fragmentos solicitamos a nuestros informantes que leyesen los textos emitiéndolos de la manera especificada por el verbo, es decir, que actuarán como si ejercieran de actores y apuntadores a la vez.

El establecimiento de la tónica natural de los informantes se ha efectuado a través de diferentes oraciones aseverativas procedentes, a su vez, de la interpretación que dichos informantes han realizado al proferir elocuciones introducidas por el verbo hlásat-proclamar, que consideramos representa un grado máximo de asertividad.

El siguiente paso ha consistido en asignarle a cada pitch una nota (musical), siguiendo la misma asignación de hercios que le otorga Gardiner a cada nota (en su estudio sobre la semántica de la prosodia checa (1980). Ésta se organiza de la siguiente manera:

\begin{tabular}{|c|c|c|c|c|c|c|c|c|c|c|c|c|}
\hline NOTA & Fa & Fa\# & Sol & Sol\# & La & La\# & Si & Do & Do\# & Re & Re\# & Mi \\
\hline $\mathrm{Hz}$ & 88 & 93 & 98 & 104 & 110 & 117 & 123 & 131 & 139 & 147 & 156 & 165 \\
\hline
\end{tabular}

Los valores de las tónicas naturales de los informantes tras proferir la elocución introducida por el verbo hlásat-proclamar es de do\# (139Hz apróx.) para Hana (informante femenina) y de fa\# (93Hz aprox.) para Ondra (informante masculino). 
A continuación damos a conocer una tabla con las distancias tonales de los intervalos de $2^{\mathrm{a}}, 3^{\mathrm{a}}$ menor y mayor, $4^{\mathrm{a}}$ y $5^{\mathrm{a}}$ justa y aumentada, entre otros, ya que dichos intervalos se han encontrado en cada una de las extracciones de habla realizadas:

\begin{tabular}{|l|c|c|c|c|c|c|c|c|c|c|c|c|}
\hline Distancia en Tonos & $1 / 2$ & 1 & $1 \frac{1}{2}$ & 2 & $2 \frac{1}{2}$ & 3 & $3 \frac{1}{2}$ & 4 & $1 / 2$ & 5 & $5 \frac{1}{2}$ & 6 \\
\hline Intervalo & $2 \mathrm{~m}$ & $2 \mathrm{M}$ & $3 \mathrm{~m}$ & $3 \mathrm{M}$ & $4 \mathrm{~J}$ & $4 \mathrm{~A}$ & $5 \mathrm{~J}$ & $5 \mathrm{~A}$ & $6 \mathrm{M}$ & $7 \mathrm{~m}$ & $7 \mathrm{M}$ & $8^{\mathrm{a}}$ \\
\hline
\end{tabular}

\section{Estudio empírico sobre la iconicidad ilocutiva de la entonación}

A través de los criterios manejados, basados en GARDINER (1980), DANEŠ (1957) y ROMPORTL (1951), hemos podido comprobar que las cadencias conclusivas descansan en la tónica. Basándonos en esta idea podemos afirmar que las tónicas de los fragmentos emitidos por los informantes para el verbo hlásat se corresponden con sus tónicas naturales.

\section{ASERTIVIDAD PROTOTÍPICA}

Hlásat: "Pokoj lidem, dobré vůle" - "Paz a los hombres de buena voluntad".
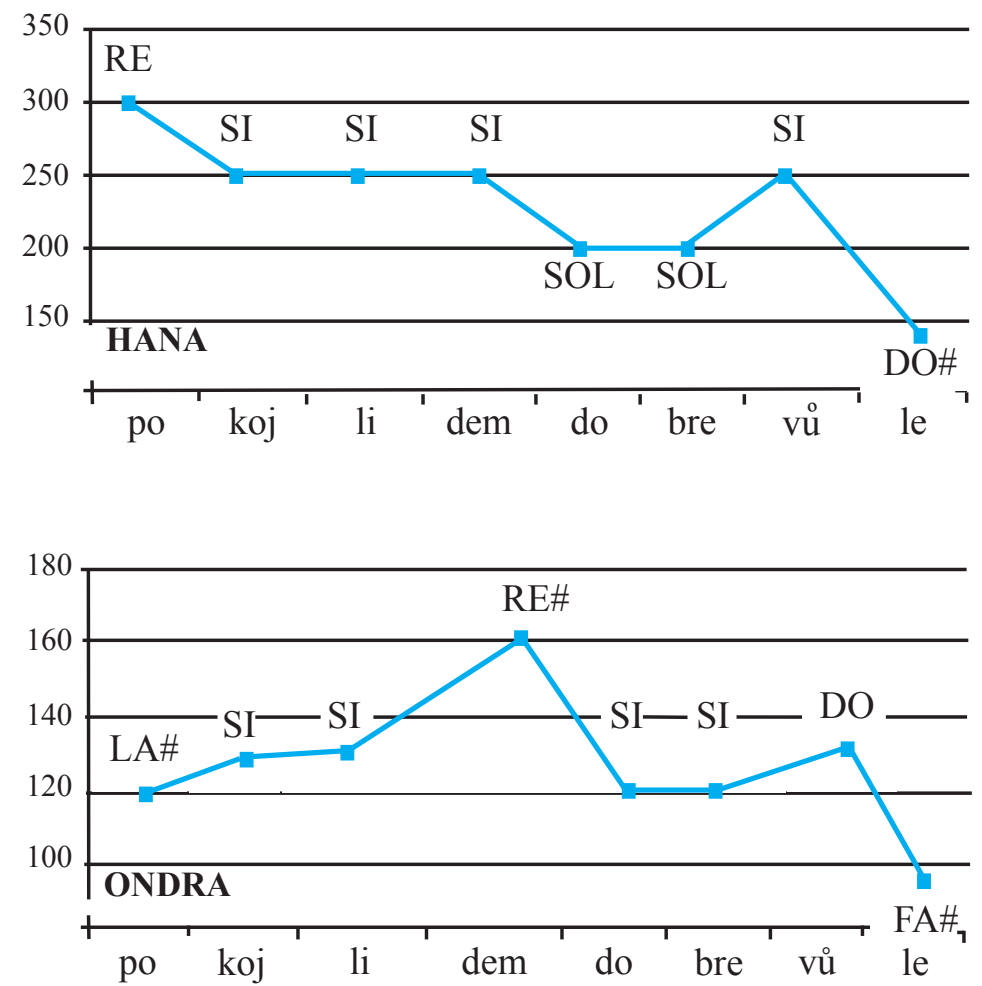
El hecho de que la fuerza ilocutiva sea interpretada como "proclamar" viene determinado por el valor interelocutivo unísono que representa, desde un punto de vista intencional y semántico, que el hablante se sitúa al mismo nivel de la aseveración que profiere.

II. SÚPLICAS, QUEJAS Y LAMENTOS EN EL ZOOMORFISMO KŇOURAT

Kňourat: "Kdepak je náš Bohoušek?" (Hana) - "Pero, ¿dónde está nuestro Bohoušek?".
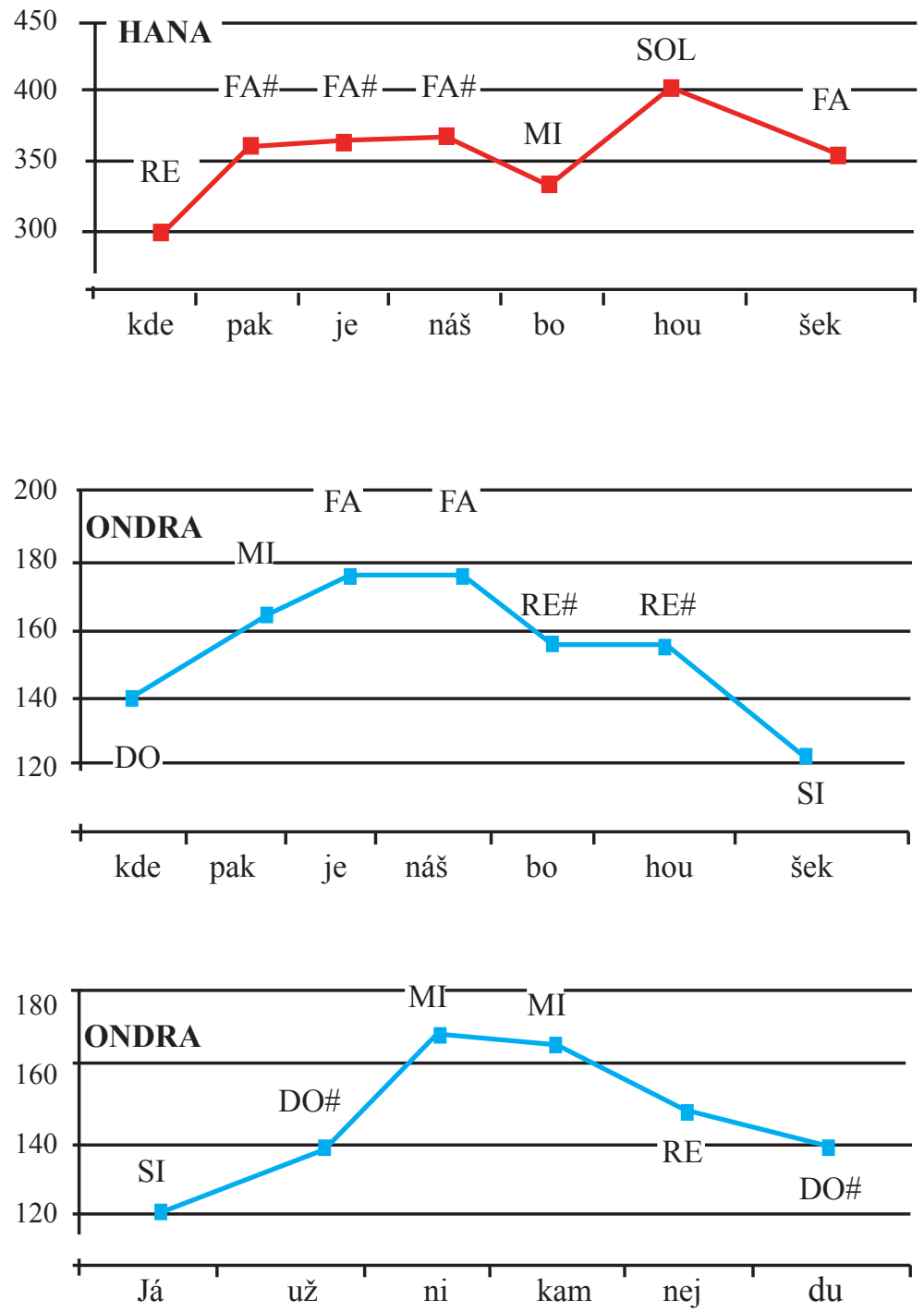


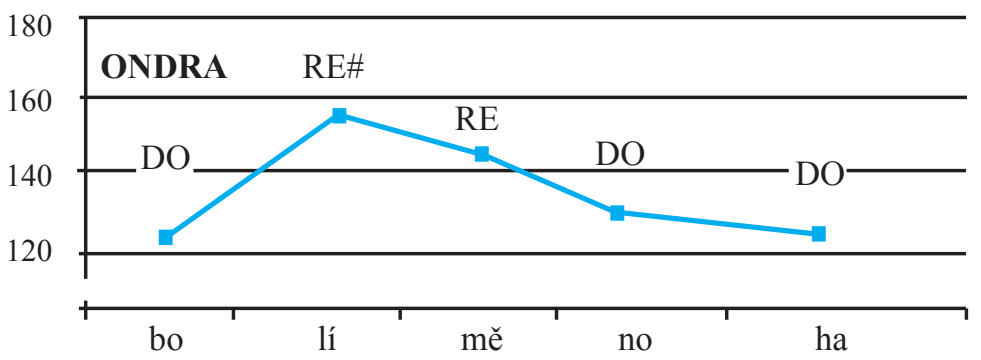

Pasamos a analizar los valores intraelocutivos e interelocutivos, así como la interpretación semántica que de los fragmentos proferidos se deriva. Somos conscientes, sin embargo, de que las frases proferidas para hlásat y kn̆ourat conllevan una modalidad oracional diferente (oración afirmativa e interrogativa), lo cual influye en la curva melódica de ambos fragmentos, aunque, por suerte, uno de los informantes continuó su elocución profiriendo una oración afirmativa. ${ }^{5}$

En el fragmento proferido por Ondra observamos que las relaciones interelocutivas entre la interrogación y la tónica natural de Ondra oscilan entre la $4 \mathrm{~J}$ y la $8^{\mathrm{a}}, \mathrm{y}$ en el segmento que se corresponde con la oración afirmativa entre la $4 \mathrm{~J}$ y la $7 \mathrm{~m}$.

En el fragmento proferido por Hana observamos que las relaciones interelocutivas durante todo el segmento oscilan entre la $4 \mathrm{~J}$ y la $4 \mathrm{~A}$, una $8^{\mathrm{a}}$ encima de su tónica natural.

Como se puede observar en ambas curvas melódicas, existen varios rasgos que indican que nos encontramos ante un acto ilocutivo suplicativo, lo que implica que la posición del hablante es inferior a la del interlocutor. Por lo tanto, la estrategia usada por el hablante para reforzar su fuerza ilocutiva conduce, paradójicamente, a la atenuación de la misma en términos de solidaridad. Reflejo de ello es la ausencia de grandes distancias entre pitches que se traduce en subidas y caídas "cromatizadas" de $4^{\mathrm{a}}$ como máximo. Hana, además, refuerza el acto subiendo su tonalidad una $8^{\mathrm{a}}$ por encima de su tónica.

Ésta es una diferencia que hemos notado durante todo el experimento. Al iniciar el experimento no contábamos con una diferencia tan relevante entre Hana y Ondra. Aunque lejos de pretender hacer un análisis fonético basado en las diferencias de género, se ha hecho patente durante todo el experimento que la actuación de Hana es más "teatral", circunstancia esta que podría tener su correlato en el carácter mímico o metarreferencial de la $8^{\mathrm{a}}$.

Creemos que la dimensión semántica “quejas" debe integrarse junto con la de "súplicas y demandas", porque ambos contenidos semánticos se expresan a través de curvas melódicas afines. De hecho, para la emisión de kňourat el informante Ondra, de manera voluntaria, continuó alargando su elocución para expresar 'queja': já už nikam nejdu-ya no voy a ningún sitio, y Bolí mě noha-me duele la pierna.

\footnotetext{
${ }^{5}$ En futuros trabajos se está realizando el mismo experimento, aunque para ratificar esta hipótesis los informantes proferirán elocuciones idénticas de manera que no exista diferencia en la modalidad oracional.
} 
A modo de conclusión, podemos aventurarnos a afirmar que existe un claro correlato entre la tonalidad y la fuerza ilocutiva. Y que dicho correlato puede ser estudiado cuando comparamos la tonalidad natural del hablante, extraída de la tónica sobre la que descansan las oraciones afirmativas emitidas en tono "aseverativo", y la tonalidad de cualquier otra elocución emitida con una intención ilocutiva diferente. También debemos advertir que en próximos estudios, para un mayor entendimiento de este fenómeno, deberemos separar gramática de entonación y/o tonalidad y retomar el experimento con elocuciones idénticas para que así no existan diferencias en la modalidad oracional.

Por otro lado, también hemos advertido que se deberán tener en cuenta otro tipo de elementos de la prosodia como son ritmo, timbre, etc., ya que junto con la curva melódica pueden indicar fuerza ilocutiva. Por ejemplo: el tono "quejoso" de las elocuciones mostradas también tiene su correlato en la falta de claridad de timbre, que en algunos casos puede interpretarse como oscuro, opaco o nasal.

\section{Referencias bibliográficas}

AUSTIN, J. L. (1962): How to Do Things with Words, Oxford University Press, Oxford.

BLANCO SALGUEIRO, A. (2008): "Cómo hacer cosas malas con palabras: actos ilocucionarios hostiles y los fundamentos de la teoría de los actos de habla", CRÍTICA, Revista hispanoamericana de Filosofia, Vol. 4, $\mathrm{N}^{\circ}$ 118, 3-27.

BOLINGER, D. (1983): “Intonation and gesture”, American Speech, 58, pp.156-184.

BUNT, H. y Y. GIRARD (2005): "Designing an Open Multidimensional Dialogue Act Taxonomy", en C. Gardent y B. Gaiffe (eds.): DIALOR'05, Proceedings of the Ninth Workshop on the Semantics and Pragmatics of Dialogue, Nancy, pp. 37-44.

CALERO DÍAZ, J. A. (2010): Análisis del dominio léxico de los verbos que expresan manera de hablar y su componente valorativo en la lengua checa, Tesis doctoral, Universidad de Granada, Granada, http://hdl.handle.net/10481/5567.

CALERO DÍAZ, J. A. (2012): "La valoración de lo metalingüístico a través de los verbos de habla checos", Eslavistica Complutense, 12, pp. 105-116.

CHAMIZO DOMÍNGUEZ, P. J. (1998): Metáfora y conocimiento, Analecta Malacitana, Universidad de Málaga, Málaga.

DANEŠ, F. (1957): "Intonace a věta ve spisovné češtině", ČsAV sekce jazyka a lit., ČSAV, Praha.

DANEŠ, F. (1973): "Verba dicendi a výpovědní funkce”, en Studia Slavica Pragensia, Praha, pp. 115-124.

DANEŠ, F. (1985): "Intonace v textu (promluvě)", $S a S, 46$, pp. 83-100.

ECHEVARRÍA ISUSQUIZA, I. (2003): "Acerca del vocabulario español de la animalización humana", Círculo de Lingüística Aplicada a la Comunicación, 15, http://www.ucm.es/info/circulo/no15/index.htm, pp. 1-28.

GARDINER, D. (1980): Intonation and Music. The Semantics of Czech Prosody, Physsardt Publications, Bloomington.

HERRERA, E. (1995): Teoría musical y armonía moderna, Vol. I, Antoni Bosch Editors.

HIRSCHOVÁ, M. (1988): Česká verba dicendi v performativním užití, (přispěvek ke zkoumání komunikativnich funkci výpovědi), Univerzita Palackého, Olomouc. 
HOLMES, J. (1984): “Modifying Illocutionary Force”, Journal of Pragmatics, 8, pp. 345-365. JURGENS BUNING, J.E. y GG.H. VAN SCHOONVELD (1961): The Sentence Intonation of Contemporary Standard Russian as a Linguistic Structure, 's-Gravenhage, Mouton \& Co. KRZESZOWSKI, T. P. (1990): “The Axiological Aspect of Idealized Cognitive Models", en J. Tomaszczyk y B. Lewandowska (eds.), Meaning and Lexicography, John Benjamins, Ámsterdam, pp. 135-165.

LAKOFF, G. (1982): "Categories and Cognitive Models", Linguistic Agency of the University of Trier, Series A. 96.

LAKOFF, G. (1987): Women, Fire, and Dangerous Things: What Categories Reveal about the Mind, University of Chicago Press, Chicago.

LAKOFF, G. y M. JOHNSON (1980a): Metaphors, we Live by, The University of Chicago Press, Chicago.

LAKOFF, G. y M. JOHNSON (1980b): “Conceptual Metaphor in Everyday Language”, The Journal of Philosophy, Vol. 77, №. 8, pp. 453-486.

LEECH, G. (1983): Principles of pragmatics, Longman, New York.

PANTHER, K. y L. THOMBURG (1998): “A cognitive approach to inferencing in conversation”, Journal of Pragmatics, 30, pp. 755-769.

PÉREZ FERNÁNDEZ, L. (1996): “The Cognition of Requests", Estudios ingleses de la Universidad Complutense, 4, Servicio de Publicaciones UCM, Madrid, pp. 189-208.

PÉREZ FERNÁNDEZ, L. (2000): “Cómo conseguir que la gente obedezca tus palabras: un análisis cognoscitivo de las órdenes en español”, REsLA, volumen monográfico, pp. 375-393.

ROMPORTL, M. (1951): K novému průběhu v mluvené češtině, Praha.

RUIZ DE MENDOZA IBÁÑEZ, F. J. (1993): "Illocution and Grammar: A Functional View", Perspectives on Semantics and Specialized Languages, Ed. C. Inchaurralde, Universidad de Zaragoza, Zaragoza, pp. 117-134.

RUIZ DE MENDOZA IBÁÑEZ, F. J. (1994): "La ilocución en la gramática funcional”, Estudios de gramática funcional, J. Martín Arista, Mira Editores, Zaragoza, pp. 149-191.

SBISÀ, M. (2001): "Illocutionary Force and Degrees of Strength in Language Use", Journal of Pragmatics, 33, pp. 1791-1814.

SEARLE, J. R. (1976): A Classification of Illocutionary Acts. Language and Society, Vol. 5, Cambridge University Press, Cambridge, pp. 1-23.

SEARLE, J. R. y D. VANDERVEKEN (1985): Foundations of Illocutionary Logic, Cambridge University Press, Cambridge.

THOMBURG, L. y K. PANTHER (1997): "Speech act metonymies", en Wolf-Andreas Liebert, Gisela Redeker and Linda Waugh, eds., Discourse and perspective in cognitive linguistics, 205-219, Benjamins, Amsterdam.

VAN SCHOONEVELD, C. H. y JURGENS BUNING, J. E. (1961): The sentence intonation of contemporary standard Russian as a linguistic structure, Mouton. 